\title{
SHOP MATHEMATICS.
}

In the December issue of the BuLLETIN there appeared a criticism of Holton's Shop Mathematics by Professor Charles $\mathrm{N}$. Haskins which was in some respects so manifestly unjust as hardly to merit a reply. But since the criticism appears in a journal for which we have always had the highest regard, and since moreover there is an implied attack upon the ideals of secondary technical education, it may be well to show wherein this criticism falls wide of its intended mark.

The fundamental error under which Professor Haskins labors is the assumption, entirely unwarranted, that this book indicates the character of the mathematical instruction in technical high schools. As a matter of fact it was prepared mainly for the use of mechanics in the shop mathematics classes of an evening trade school, and finds simply an incidental, though very valuable, use in the (day) Technical High School, which is a school of full academic training, preparing students not only for industrial work directly but also for further study in the highest technical schools and colleges in the country. To meet the admission requirements of these institutions it is obviously necessary to give full courses in mathematics. And entirely aside from the preparatory courses no sensible teacher would fail to recognize the value of the purely mathematical element as a basis for application in the industries, as Professor Haskins points out at the close of his paper. This is not only assumed, but it is emphasized in all strong technical courses. The unfairness, or perhaps I should say the inaccuracy, of Professor Haskins's charge appears plainly in a sentence on page 138 in which he quotes, or misquotes, from the introduction a sentence which as there printed reads, "No attempt is made in this book to teach mathematical theory or principles." That is true. No such attempt is made in this book; for the purpose of the book does not require it. But Professor Haskins leaves out the phrase "in this book" and suggests that the author of the introduction was referring to the "character of the mathematical instruction in such schools." Professor Haskins therefore apparently misunderstood not only the kind of school for which the book was mainly intended,- - viz., a trade school - but also the use which is actually made of it in the Technical High School-mistakes which really take away all the point in his attempt at serious criticism. 
And yet there seems to be an element of unfairness in the general spirit of the criticism which should not go unchallenged. Professor Haskins assumes so much ignorance of practical affairs on the part of the author of this book, who is really a very practical man, and gives such a ridiculous turn to some of the problems selected for criticism as to provoke amazement, if not laughter, at the expense of the critic himself. For example, note the remarks about problem 17 on the raising of a building by means of jack screws. Now that was a problem based on facts. It was involved in the moving of one of our large public buildings within a stone's throw of the Springfield Technical High School. There were actually one hundred $1 / 4$ inch lead jack screws used; but it is by no means necessary to assume that there were one hundred men concerned in this operation, - one stationed at each jack screw. As a matter of fact there were five men, one for each of the five rows of jack screws, who operated each of the twenty jack screws in his row in order, giving a short turn at a time to each; and thus the building, which was a brick building, was successfully raised and moved. There is really no occasion for ridicule,-for comparing the force used to that exerted by bending the "little finger," or for comparing the bar with a "pen holder"; and it is inconceivable to the writer how anyone could find in this problem the necessary conception of one hundred laborers employed. And yet this ridiculous conception seems to have been suggested to Professor Haskins's mind by this by no means unusual case of lifting a brick building.

Turning now to the computations involved in this problem, it would hardly seem to be necessary to point out that this was not really given as a problem of computation that would occur in actual practice. It was expressly stated at the beginning that the element of friction was left out. It was therefore not intended to be a complete and actual problem at all. In fact, no contractor would need to figure out the length of these jack screw bars or the force required. For him and for most workmen such a matter is one of judgment acquired by experience. The problem was obviously chosen to illustrate the underlying operating principles of jack screws as expressed in the formula; and for this purpose there is certainly no harm in getting a computed result to thousandths of an inch. It is convenient to have such answers in order to test up the 
accuracy of the arithmetical work of men in trade schools; for they need practice in computation quite as much as they need anything. But there is hardly one of these men who would not laugh down the critic who assumes that the author, or even they themselves, would be so lacking in common sense as to consider such a computed result as finding actual application in the practice of raising buildings. The interest of this problem for these men obviously consists in the insight it gives into the meaning of a certain mechanical formula. It is for the engineer, or for the workman who aspires to become an engineer, to make corrections for friction and figure out, if necessary, the value of the force that could actually be applied with a jack screw of known dimensions and determine the number required. But that is an entirely different matter.

The same reply may be given in general to the second criticism upon problem 12, page 51. Here again the main purpose is to illustrate the combination of several formulas; and the calculation is carried to its full extent in order that the work of the several members of the class may be checked up for accuracy. Friction is disregarded, the effort being to illustrate the mathematical basis on which practical work depends. Practical work itself would obviously involve many corrections for friction and other losses and imply approximate results.

Again in the criticism of the problem on spiral gears (page 45) Professor Haskins finds in this a good example of how not to apply mathematical formulas in the solution of such problems because, as he says, the method of solution given involves first multiplying by $\pi$ and then dividing by $\pi$. Obviously this is unnecessary in a mathematical computation to find one result,-as, for example, the number of teeth. As a matter of fact, however, in this problem four results have to be found, viz., the circular pitch, the number of teeth, the blank diameter, and the lead of the spiral, all four of which results must be known in order to set up the machine to cut the gears. This is plainly indicated in the problem as given in the book under criticism in the words, "Calculate the other dimensions of the gears." Professor Haskins chooses to state the problem as one to determine the number of teeth (N) only,-a gross misstatement which, it would seem, could hardly have been made for any other purpose than to manufacture a point against the book. And yet we wish to be charitable. One 
accustomed to think along the lines of pure mathematics only would not, of course, appreciate the real meaning of the mathematical layout of this problem; and it is to be presumed that this is Professor Haskins's real difficulty. He deprecates unnecessary mathematical work; and so do we. Short cuts in arithmetical computations are of course desirable if the workmen can be safely trusted to carry them out; but practical teachers find that it is not wise to dwell much upon short cuts in the elementary stages of the work. Since most of the men who use this book are far from being experts in computation, short cuts would be on the whole confusing, though of course when they are not confusing they are to be recommended. The kind of formalism Professor Haskins criticizes is not "excessive" and "pernicious" so long as it is necessary for a thorough understanding of the processes of computation.

Technical High School,

Charles F. Warner. SPRINGFIELD, Mass.

The above statements may be answered as follows:

(1) The review is said to contain "an implied attack on the ideals of secondary technical education." On the contrary those ideals, as stated by Dr. Woodward, were explicitly assumed as a standard by which the book was tested.

(2) With reference to the quotation on page 138 it would appear that since the sentence in question begins "Let us test the book before $u s^{*}$ by this standard, remembering that $i t{ }^{*}$ object is etc.," the significance of the passage is the same whether the words "in this book" be omitted from the quotation or included therein.

(3) The reviewer hopes that the assumption that the book indicates the character of the instruction in secondary technical schools is unwarranted, but contends that a form of instruction which for the sake of convenience in testing the accuracy of the pupil's arithmetical work finds "no harm in getting a computed result to thousandths of an inch," when that result is the length of a jack-screw bar, effectually deprives the pupil of any real insight "into the meaning of a certain mathematical formula," and is pernicious formalism in that it does not compel the pupil to consider the significance and reasonableness of the numerical data and results.

\footnotetext{
sary.

*The italics were not in the review as printed. They seemed unneces-
} 
(4) The jack-screw problem is said to be "a problem based on facts." Granted. Also "it was . . . not intended to be a complete and actual problem at all," and it is implied that one would be "lacking in common sense" "to consider such a computed result as finding actual application in the practice of raising buildings." Exactly. That was why it was chosen for criticism. The book aims to show the pupil "what the shop problems are."*

(5) The reviewer is accused of "gross misstatement" of the problem on spiral gearing and malicious intent on his part is implied. The reviewer would point out that of the four results above mentioned, one, the lead of the spiral, is not even mentioned in the solution of the problem as given by the author of the book. The other three quantities may be determined by the formulas: number of teeth $=N=D p$ $\cos Y$, blank diameter $=D+2 / p$, circular pitch $=\pi / p \cos Y$. Whether any single one or all three of these quantities are to be found from the given data, the determination does not involve operations equivalent to multiplication followed by division by $\pi$. This is true also of the determination of the dimensions of the driven gear, and of the numbers of the milling cutters to be used, both of which are given in the book, though not mentioned above. The question at issue is not one of "short cuts" in computation, but of comprehension of the principles and formulas underlying the computation. The reviewer sees no cause to retract any portion of his criticism of the problem.

Charles N. Haskins.

\section{SHORTER NOTICES.}

Arithmétique générale. Par Emile Dumont. Paris, A. Hermann et Fils, 1911. 8vo. xvii+275 pp. 10 francs.

THIs volume presents a treatment of certain number fields and the ordinary laws of operation within these fields. The book is divided into four parts, of which the first treats of

*Introduction, p. viii. 